\title{
Gastric peroxisome proliferator activator receptor- $\gamma$ expression and cytoprotective actions of its ligands against ischemia-reperfusion injury in rats
}

\author{
Yuji Naito, * Tomohisa Takagi, Kazuhiro Katada, Naoya Tomatsuri, Katsura Mizushima, Osamu Handa, \\ Satoshi Kokura, Nobuaki Yagi, Hiroshi Ichikawa and Toshikazu Yoshikawa \\ Department of Molecular Gastroenterology and Hepatology, Kyoto Prefectural University of Medicine, Kamigyo-ku, Kyoto 602-8566, Japan
}

(Received 6 July, 2010; Accepted 13 July, 2010; Published online 26 February, 2011)

\begin{abstract}
The beneficial effects by peroxisome proliferator-activated receptor$\gamma$ (PPAR- $\gamma$ ) on gastric injury induced by ischemia-reperfusion have been confirmed, however, the precise mechanism of its cytoprotection is not elucidated thoroughly. The aim of the present study was to determine the gastric localization of PPAR- $\gamma$ expression in the rat gastric mucosa, and to clarify the mechanism of its cytoprotective properties. The gastric expression of PPAR- $\gamma$ was confirmed by RT-PCR and western blot, and localized on gastric epithelial cells. The protective effect of PPAR- $\gamma$ ligands, pioglitazone or 15-deoxy- $\Delta^{12,14}$-prostaglandin $J_{2}$, on gastric ischemia-reperfusion injury was reversed by the co-administration with PPAR- $\gamma$ antagonist. The gastric expression of tumor necrosis factor- $\alpha$ and cytokine-induced neutrophil chemoattractant-1 increased significantly in rats treated ischemia-reperfusion, and these increases were significantly inhibited by treatment with pioglitazone. Among the 1,032 probes, 18 probes were up-regulated at least 1.5-fold, 17 were down-regulated at least 1.5 -fold by pioglitazone. The network including calnexin, endoplasmic reticulum stress protein, heat shock proteins, and proteasome genes was induced by pioglitazone treatment. In conclusion, activation of gastric epithelial PPAR- $\gamma$ receptor by its ligands may represent a novel therapeutic approach for gastric inflammation via up-regulation of heat shock proteins and endoplasmic reticulum-related proteins.
\end{abstract}

Key Words: DNA microarray, inflammation, ischemia-reperfusion, peroxisome proliferator-activated receptor- $\gamma$ (PPAR- $\gamma$ ), transcriptome

$\mathrm{T}$ he signaling of ischemia or ischemia-reperfusion (I-R) is a major contributing condition leading to gastric mucosal injury induced by stress, ${ }^{(1,2)}$ non-steroidal anti-inflammatory drugs (NSAIDs), ${ }^{(3)}$ and Helicobacter pylori infection. ${ }^{(4)}$ Gastric I-R causes mucosal ulcerative lesions as well as acute inflammation associated with neutrophil accumulation. ${ }^{(5-7)}$ Previous studies have demonstrated that the infiltration of neutrophils into gastric tissue via neutrophil-endothelial cell interactions plays a critical role in the pathogenesis of I-R-induced gastric injury, because neutrophils generate tissue damage factors such as reactive oxygen species and proteases. ${ }^{(6,8)}$ Neutrophil accumulation is a complex phenomenon that also involves various adhesion molecules and inflammatory mediators. Using a rat model of gastric I-R, we have revealed that reactive oxygen species play a crucial role in the pathogenesis of reperfusion-induced mucosal injury. ${ }^{(6,7)}$ In addition to reactive oxygen species, a variety of cytokines, including interleukin-8 (IL-8), tumor necrosis factor- $\alpha$ (TNF- $\alpha$ ), and IL-1 $\beta$, are released from post-ischemic gastric tissue to modulate tissue repair and adaptation. These cytokines are elaborated soon after gastric ischemic injury and can acutely regulate gastric mucosal survival or apoptosis and trigger additional cellular inflammatory response.

The peroxisome proliferator-activated receptors (PPARs) are members of the nuclear receptor supergene family that function in ligand-activated transcription. ${ }^{(9,10)}$ PPARs consist of at least three isoforms, $\alpha, \beta$, and $\gamma$, encoded by unique genes. Among them, PPAR $-\gamma$ is highly expressed in adipose tissue, colon, spleen, adrenal gland, and macrophages. Previous studies have demonstrated that the naturally occurring arachidonic acid metabolite, 15 -deoxy- $\Delta^{12,14}$-prostaglandin $\mathrm{J}_{2}\left(15 \mathrm{~d}-\mathrm{PGJ}_{2}\right)$, as well as thiazolidinedione (TZD) and certain novel non-TZD insulin-sensitizing agents, are ligands and agonist of this receptor. Although PPAR- $\gamma$ play a key role in adipose differentiation, lipid metabolism, and glucose homeostasis, recent studies suggest that they might be involved in the control of inflammation and especially in the modulation of the expression of various cytokines in monocytes and macrophages. ${ }^{(11-13)}$

Recently, our group and others reported that PPAR- $\gamma$ plays an anti-inflammatory role in gastric inflammation induced by $\mathrm{I}-\mathrm{R},{ }^{(14-18)}$ aspirin, ${ }^{(19)}$ and Helicobacter pylori infection ${ }^{(20)}$ in rats. In 2001, we firstly demonstrated that pioglitazone, a synthetic TZD, markedly reduced gastric erosions induced by aspirin as well as inhibited the enhanced expression of pro-inflammatory cytokine TNF- $\alpha .^{(19)}$ In addition, we have reported the gastric cytoprotection by pioglitazone and $15 \mathrm{~d}-\mathrm{PGJ}_{2}$ against I-R injury, associated with anti-inflammatory actions of these ligands. ${ }^{(14,18)}$ This beneficial effects by PPAR- $\gamma$ ligands on I-R-induced gastric injury have been also confirmed by several investigators, however, the precise mechanism of the cytoprotection in vivo is not elucidated thoroughly. In addition, Nakajima et al. ${ }^{(21)}$ showed that no expression of PPAR- $\gamma$ could be detected by Western blot analysis in the rat stomach.

On the basis of these observations, we determined the gastric localization of PPAR- $\gamma$ expression in the rat gastric mucosa, and examined whether GW9662, an antagonist of PPAR- $\gamma$, can attenuate the protective effects of pioglitazone and $15 \mathrm{~d}-\mathrm{PGJ}_{2}$ in order to elucidate whether the protective effects of these ligands are related to the activation of the PPAR $-\gamma$ receptor. Finally, to clarify the mechanism of cytoprotective properties of pioglitazone, we performed a global analysis of gene expression in the gastric mucosal cells of rats treated with pioglitazone.

*To whom correspondence should be addressed.

E-mail: ynaito@koto.kpu-m.ac.jp 


\section{Materials and Methods}

Reagents. All chemicals were prepared immediately before use. Pioglitazone was donated from Takeda Pharmaceutical Co., Ltd. (Osaka, Japan). 15d-PGJ 2 and GW9662 were obtained from Cayman Chemical Co. (Ann Arbor, MI) and Sigma-Aldrich Japan Inc. (Tokyo, Japan), respectively. PPAR- $\gamma$ polyclonal antibody (sc-6285) was purchased from Santa Cruz Biotech. (Santa Cruz, CA). Isogen was purchased from Nippon Gene (Tokyo, Japan), and Taq DNA polymerase was from Takara Shuzo Co. (Shiga, Japan). Enzyme-linked immunosorbent assay (ELISA) kits for TNF- $\alpha$ and CINC-1 were obtained from BioSource Int. (Camarillo, CA) and Immuno-Biological Laboratories Co. (Gunma, Japan). All other chemicals used were of reagent grade.

Preparation of rats for acute gastric mucosal injury induced by ischemia-reperfusion. Male Sprague-Dawley rats weighing 190-210 g were obtained from Keari Co. Ltd. (Osaka, Japan). They were housed in stainless steel cages with wire bottoms and maintained on a 12-h light and 12-h dark cycle with the temperature and relative humidity of the animal room controlled at $21-23^{\circ} \mathrm{C}$ and $55-65 \%$, respectively. They were not fed for $18 \mathrm{~h}$ prior to the experiments, but were allowed free access to water. Maintenance of animals and experimental procedures were carried out in accordance with the US National Institutes of Health Guidelines for the Use of Experimental Animals. All experiments were approved by the Animal Care Committee of Kyoto Prefectural University of Medicine (Kyoto, Japan). After animals were given intraperitoneal urethane anesthesia (1000 $\mathrm{mg} / \mathrm{kg}$ ), gastric ischemia was induced by applying a small clamp to the celiac artery for $30 \mathrm{~min}$, followed by the removal of the clamp for $60 \mathrm{~min}$ according to the previously reported method. ${ }^{(6)}$ Pioglitazone dissolved in $0.5 \%$ carboxymethyl cellulose (CMC) and $15 \mathrm{~d}-\mathrm{PGJ}_{2}$ dissolved in physiological saline were given to the rats by gastric intubation $1 \mathrm{~h}$ before the vascular clamping. To evaluate the effect of agents on ischemia-reperfusion injury, mice were divided into the following groups: 1) sham-operated mice receiving $0.5 \% \mathrm{CMC}$ solution, 2 ) I-R-treated mice receiving $0.5 \%$ CMC solution, 3) sham-operated mice receiving pioglitazone or $15 \mathrm{~d}-\mathrm{PGJ}_{2}$, and 4) I-R-treated mice receiving pioglitazone or $15 \mathrm{~d}-\mathrm{PGJ}_{2}$. A specific PPAR- $\gamma$ antagonist GW9662 dissolved in physiological saline was also given to rats intraperitoneally $2 \mathrm{~h}$ before the vascular clamping.

Assessment of gastric mucosal injury induced by ischemia-reperfusion. To estimate the severity of the gastric erosions induced by I-R, the total area of the red gastric lesions that was measured using a dissecting microscope $(\times 10$ magnification) with a square grid by a person blinded to the treatment. The extent of any gastric mucosal lesions was expressed in terms of the total area $\left(\mathrm{mm}^{2}\right)$ of hemorrhagic erosions. Removed tissues were fixed in $15 \%$ formaldehyde, embedded in paraffin, and sectioned (5- $\mu \mathrm{m}$ slices), and the sections were stained with hematoxylin eosin and viewed by an investigator blinded to the treatment.

Cell culture and preparation for anoxia-reoxygenation. The rat gastric mucosal cell line RGM-1 (RCB-0876 at Riken Cell Bank, Tsukuba, Japan), established by Matsui and Ohno, ${ }^{(22)}$ was used for the present study. The RGM-1 cells were grown in Dulbecco's modified Eagle's medium (DMEM; Gibco Laboratories, Grand Island, NY) containing $10 \%$ fetal bovine serum and antibiotics $(100 \mathrm{U} / \mathrm{ml}$ penicillin, $100 \mu \mathrm{g} / \mathrm{ml}$ streptomycin, and $0.125 \mu \mathrm{g} / \mathrm{ml}$ amphotericin B). Cell cultures were incubated in atmospheric air with $5 \% \mathrm{CO}_{2}$ at $37^{\circ} \mathrm{C}$. Confluent RGM-1 monolayers were exposed to hypoxia by incubation in Plexigas chamber that was continuously purged $(1 \mathrm{l} / \mathrm{min})$ with an anoxic gas mixture $\left(95 \% \mathrm{~N}_{2}+5 \% \mathrm{CO}_{2}\right)$, according to a method reported in a previous study. ${ }^{(23,24)}$ After a 120-min period of hypoxia, reoxygenation was initiated by exposure the cells to atmospheric air with $5 \% \mathrm{CO}_{2}$ at $37^{\circ} \mathrm{C}$ for $8 \mathrm{~h}$. When we pretreated RGM-1 cells with pioglitazone, we applied 1 and $10 \mu \mathrm{M}$ pioglitazone dissolved in $0.5 \%$ dimethyl- sulfoxide into the culture media for $60 \mathrm{~min}$ before anoxia treatment.

Immunohistochemistry for PPAR- $\gamma$. Expression and localization of PPAR- $\gamma$ in gastric tissue was detected by standard immunohistochemical techniques using anti-PPAR- $\gamma$ polyclonal antibody on paraffin sections. The $\mathrm{mAb}$ were diluted in PBS solutions containing $1 \%$ BSA and $0.1 \%$ Triton X-100 and applied for overnight at $4{ }^{\circ} \mathrm{C}$. The sections were then incubated with biotinylated anti-mouse IgG (Vectastatin Elite ABC kit, Vector Laboratories) for $30 \mathrm{~min}$. After they were washed, the specimens were incubated with a mixture of avidin and horseradish peroxideconjugated biotin for $30 \mathrm{~min}$ and were reacted with 3,3'-diaminobenzidine tetrahydrochloride at $0.2 \mathrm{mg} / \mathrm{ml}$ and $0.005 \% \mathrm{H}_{2} \mathrm{O}_{2}$ in Tris buffer. Nonimmune mouse $\operatorname{IgG}$ was used as a negative control.

Reversed transcription-polymerase chain reaction (RTPCR). For the evaluation of PPAR- $\gamma$, TNF- $\alpha$ and CINC- 1 mRNA, the gastric wall of rats was rinsed in PBS, snap-frozen in liquid nitrogen, and then stored at $-80^{\circ} \mathrm{C}$ until the time of RNA extraction. Total RNA was isolated from the gastric mucosal with the acid guanidinium phenol chloroform method using an Isogen kit (Nippon Gene, Tokyo, Japan). The concentration of RNA was determined by absorbance at $260 \mathrm{~nm}$ in relation to absorbance at $280 \mathrm{~nm}$. RNA was stored at $-70^{\circ} \mathrm{C}$ until reverse transcription was performed. The RNA was used for reverse-transcription polymerase chain reaction (RT-PCR) amplification. The amplification was carried out in a $50 \mu \mathrm{l}$-mixture containing $2 \mu \mathrm{l}$ of the RT product, $0.6 \mu \mathrm{M}$ of both the sense and antisense primers, $0.4 \mathrm{mM}$ dNTP mix, and $0.5 \mu 1$ Taq DNA polymerase (Takara Shuzo Co., Shiga, Japan). The reaction was performed as follows: 35 cycles of amplication (denaturation at $94^{\circ} \mathrm{C}$ for $30 \mathrm{~s}$, annealing at $50^{\circ} \mathrm{C}$ for $30 \mathrm{~s}$, and extension at $72^{\circ} \mathrm{C}$ for $60 \mathrm{~s}$ ), followed by a final extension step of $7 \mathrm{~min}$ at $72^{\circ} \mathrm{C}$. Sequences for primers were: PPAR- $\gamma$ forward primer 5'-ATCGTGGGCCGCCCTAGGCA-3'; PPAR- $\gamma$ reverse primer 5'-TGGCCTTAGGGTTCAGAGGGG-3'; TNF- $\alpha$, forward primer 5'-ATGAGCACAGAAAGCATGATC-3'; TNF- $\alpha$, reverse primer 5'-TACAGGCTTGTCACTCGAATT-3'; CINC-1 forward primer sense 5'-CTGTGCTGGCCACCAGCCGC-3'; CINC-1 reverse primer 5'-ACAGTCCTTGGAACTTCTCTG-3'; and $\beta$-actin forward primer; 5'-ATCGTGGGCCGCCCTAGGCA3'; $\beta$-actin reversed primer 5'-TGGCCTTAGGGTTCAGAG GGG-3'. The PCR reaction products were separated electrophoretically in a $2.5 \%$ agarose gel and stained by ethidium bromide.

Quantitative real-time PCR. After $2 \mathrm{~h}$ of administration with vehicle solution or pioglitazone $(10 \mathrm{mg} / \mathrm{kg})$, total RNA was isolated from the gastric mucosal with the acid guanidinium phenol chloroform method using an Isogen kit (Nippon Gene). An aliquot $(1 \mu \mathrm{g})$ of extract RNA was reverse-transcribed into first-strand complementary DNA (cDNA) at $42^{\circ} \mathrm{C}$ for $40 \mathrm{~min}$, using $100 \mathrm{U} / \mathrm{ml}$ reverse-transcriptase (Takara Biochemicals, Shiga, Japan) and $0.1 \mu \mathrm{M}$ of oligo (dT)-adapter primer (Takara) in a $50 \mu \mathrm{L}$ reaction mixture. Real-time polymerase chain reaction (PCR) was carried out with a 7300 Real Time PCR system (Applied Biosystems, Foster City, CA) using the DNA-binding dye SYBER Green I for the detection of PCR products according to the manufacturer's instructions. The reaction mixture (RT-PCR kit, Code RRO43A, Takara) contained $12.5 \mu \mathrm{l}$ Premix Ex Taq, $2.5 \mu$ l SYBER Green I, custom-synthesized primers, ROX reference dye, cDNA (equivalent to $20 \mathrm{ng}$ total RNA) to give a final reaction volume of $25 \mu \mathrm{l}$. Sequences for primers were: calnexin (CANX) forward primer 5'-TGCCATCTCTGCTAAACTGAACA-3'; CANX reverse primer 5'-CACCACCGCATT CTATTCCA-3'; endoplasmic reticulum stress protein 72 (ERP70) forward primer 5'-ATGCTCTCCGAG AATTTGTCATG-3'; ERP70 reverse primer 5'-CACCCTGACTG GTCCCTTGT-3'; heat-shock $70 \mathrm{kD}$ protein 5 (HSPA5) forward primer 5'-CCATCACCAATGACCAAAACC-3'; HSPA5 reverse primer 5'-GCGCTCTTTGAGCTTTTTGTC-3'; heat-shock protein 86 (HSPCA) forward primer 5'-CAGGCAGAAATTGCCCAGTT- 
3'; HSPCA reverse primer 5'-AGAGCGTCTGAGGAGTTGG AAA-3'; proteasome subunit beta type4 (PSMB4) forward primer 5'-GAAGCAAGTTCTCGGCCAGAT-3'; PSMB4 reverse primer 5'-ACATGGCCCTTGTCAACCA-3'; and $\beta$-actin forward primer 5'-GAGCAAACATCCCCCAAAGTT-3'; $\beta$-actin reverse primer 5'-GCCGTGGATACTTGGAGTGACT-3'. The PCR settings were as follows: initial denaturation of $10 \mathrm{~s}$ at $95^{\circ} \mathrm{C}$ was followed by 40 cycle of amplification for $5 \mathrm{~s}$ at $95^{\circ} \mathrm{C}$ and $31 \mathrm{~s}$ at $60^{\circ} \mathrm{C}$. Real-time PCR was performed with universal cycling conditions $(2 \mathrm{~min}$ at $50^{\circ} \mathrm{C}, 10 \mathrm{~min}$ at $95^{\circ} \mathrm{C}, 40$ cycles of $15 \mathrm{~s}$ at $95^{\circ} \mathrm{C}$, and $1 \mathrm{~min}$ at $60^{\circ} \mathrm{C}$ ). Data were analyzed using ABI Prism 7300 SDS Software (Applied Biosystems). Standard curves relating initial template copy number to fluorescence and amplification cycle were generated using the amplified PCR product as a template, and were used to calculate mRNA copy number in each sample. Ratios of the intensities of the $\beta$-actin signals were used as a relative measure of the expression level of each specimen.

Western blotting. The frozen tissue from rat stomach was thawed on ice and homogenized at $4^{\circ} \mathrm{C}$ in a solution of $50 \mathrm{mmol} / 1$ Tris-HCl, pH 7.6, $300 \mathrm{mmol} / \mathrm{l} \mathrm{NaCl}, 0.5 \%$ Triton X-100, $10 \mathrm{mg} / \mathrm{ml}$ aprotinin, $10 \mathrm{mg} / \mathrm{ml}$ leuptin, $1 \mathrm{mmol} / 1 \mathrm{PMSF}, 1.8 \mathrm{mg} / \mathrm{ml}$ iodoacetamide, $50 \mathrm{mmol} / \mathrm{l} \mathrm{NaF}$, and $1 \mathrm{mM}$ DTT for extracting total cell protein. Proteins were separated by sodium dodecyl sulfatepolyacrylamide gel electrophoresis (SDS-PAGE) and transferred onto nitrocellulose (Bio-Rad Laboratories, Hercules, CA). Membranes were probed with polyclonal antibody against PPAR- $\gamma$ (Santa Cruz Biotechnology Inc. Santa Cruz, CA). The immune complexes were visualized by Western blotting with a commercial kit (ECL by Amersham, BuckinghamshI-Re, England) according to the manufacturer's recommendations.

Measurements of TNF- $\alpha$ and CINC-1. The concentrations of inflammatory cytokines (TNF- $\alpha$ and CINC-1) in the supernatant of mucosal homogenates and cell culture medium were determined by rat TNF- $\alpha$ and CINC-1 specific enzyme-linked immunosorbent assay (ELISA) kits according to the manufacturer's instructions.

Laser capture microdissection, isolation of RNA, CDNA synthesis, cRNA amplification, and GeneChip hybridization. We used laser-assisted microdissection to obtain cellspecific RNA. Gastric epithelial cells were identified on cryostat sections $(8 \mu \mathrm{m})$ of the specimens obtained from the stomach of the rat, and the cells were isolated by laser-assisted microdissection using an LM200 system (Olympus, Tokyo, Japan). A sample containing several hundred cells was collected from each stomach. According to the Affymetrix GeneChip Eukaryotic Small Sample Target Labeling Assay protocol (Version II). Using this protocol, we succeeded in obtaining a sufficient amount of biotinylated cRNA to perform the GeneChip analysis from the small amount of gastric epithelial cells obtained by laser captured microdissection. ${ }^{(25)}$ Labeled cRNA target was cleaned up using RNeasy columns. The fragmentation, hybridization, washing, and staining were carried out according to the instructions described in the GeneChip Expression Analysis Technical Manual. Affymetrix GeneChip arrays (Affymetrix, Santa Clara, CA) were hybridized with the biotinylated products $(5 \mu \mathrm{g} / \mathrm{chip})$ for $16 \mathrm{~h}$ at $45^{\circ} \mathrm{C}$ using the manufacturer's hybridization buffer. After washing the arrays, hybridized RNA was detected by staining with streptavidinphycoery-thrin. The DNA chips were scanned using a specially designed confocal scanner (GeneChip Scanenr 3000, Affymetrix).

Statistics. Data of total area of erosions, contents of cytokines, and real-time PCR analysis are expressed as mean (SEM). Oneway analysis of variance (ANOVA) with Scheffe's multiple comparison test was performed when more than two groups were compared. Differences in mRNA expression determined by realtime PCR between vehicle and pioglitazone treatments were determined by Student's $t$ test. A $p$ value of $<0.05$ was considered statistically significant. All analyses were performed using Stat View 5.0-J program (Abacus Concepts Inc. Berkeley, CA) on a Macintosh computer.
Array data analysis was carried out using Affymetrix GeneChip Operating Software (GCOS) version 1.0. GCOS analyzes image data and computes an intensity value for each probe cell. Briefly, mismatch probes act as specificity controls that allow the direct subtraction of both background and cross-hybridization signals. To determine the quantitative RNA abundance, the average difference values (i.e., gene expression levels) representing the perfect match-mismatch for each gene-specific probe family is calculated, and the fold changes in average difference values were determined according to Affymetrix algorithms and procedures. For the pathway analysis, gene probe set ID numbers were imported into the Ingenuity Pathway Analysis software (Ingenuity Systems, Mountain View, CA). The identified genes were mapped to genetic networks available in the Ingenuity database and were then ranked by a score. The score is the probability that a collection of genes is equal to or greater than the number in a network that could be achieved by chance alone. A score of 3 indicates that there is a $1 / 1000$ chance (significance $=0.001$ ) that the focus genes are in a network randomly. Therefore, gene sets with scores of 3 or higher have a $99.9 \%$ confidence of not being randomly generated. This score was used as the cut-off for identifying gene networks significantly affected by indomethacin.

\section{Results}

Expression of PPAR- $\gamma$ in rat gastric mucosa. To identify the localization of PPAR- $\gamma$ within stomach, we performed immunohistochemical analysis of PPAR- $\gamma$ protein. As shown in Fig. 1a, the expression of PPAR- $\gamma$ was observed in mucosal epithelial cells and parietal cells. Using cultured rat gastric mucosal cells (RGM-1), the nuclear-dominant localization of PPAR- $\gamma$ was confirmed (Fig. 1 b and c), although the levels of PPAR- $\gamma$ expression in normal gastric mucosal cells was much lower than those of gastric cancer cells. Western blotting also showed the clear expression of PPAR- $\gamma$ in the rat gastric mucosa (Fig. 1f), and its levels were not changed by I-R but slightly increased by the treatment with pioglitazone. RT-PCR also demonstrated the PPAR $-\gamma$ mRNA expression in the gastric mucosa (Fig. 1g). The expression levels were slightly decreased after I-R.

Effect of PPAR- $\gamma$ ligands and antagonist on I-R-induced gastric mucosal injury. According to our previous studies ${ }^{(14,18)}$ in which pre-treatment with pioglitazone or $15 \mathrm{~d}-\mathrm{PGJ}_{2} 1 \mathrm{~h}$ before the ischemia inhibited I-R-induced gastric mucosal injury in a dose-dependent manner, we used pioglitazone at a dose of $10 \mathrm{mg} / \mathrm{kg}$ and $15 \mathrm{~d}-\mathrm{PGJ}_{2}$ at a dose of $0.3 \mathrm{mg} / \mathrm{kg}$ and examined its pharmacological action in the present study. Neither ligand alone nor GW9662, a PPAR- $\gamma$ antagonist, alone produced any macroscopic lesions in the rat stomach. I-R resulted in increase in total area of erosions developed in the glandular stomach. Both pioglitazone and $15 \mathrm{~d}-\mathrm{PGJ}_{2}$ significantly reduced the increase in total area of erosions after I-R, and the protective effect of these ligands was almost completely reversed by the co-administration with GW9662 (Fig. 2). The protective effect of pioglitazone and $15 \mathrm{~d}_{-}-\mathrm{PGJ}_{2}$ was confirmed histologically (data not shown). I-R resulted in large areas of epithelial crypt loss, predominantly neutrophilic infiltrate throughout the mucosa and submucosa, erosion, and mucosal bleeding. In contrast, pretreatment with pioglitazone or $15 \mathrm{~d}-\mathrm{PGJ}_{2}$ resulted in smaller erosions with few neutrophils.

Effects of pioglitazone on mucosal contents and mRNA expression of TNF- $\alpha$ and CINC-1 after I-R, and on the CINC-1 production from stimulated gastric epithelial cells. To test if pioglitazone treatment could modulate the inflammatory response through regulation of cytokine production, we analyzed gastric mucosal levels of TNF- $\alpha$ and CINC-1. The gastric concentrations of TNF- $\alpha$ and CINC-1 increased significantly in rats treated I-R, and these increases were significantly inhibited by treatment with pioglitazone at a dose of $10 \mathrm{mg} / \mathrm{kg}$ (Fig. $3 \mathrm{a}$ and b). To further confirm the inhibitory effect of pioglitazone on TNF- $\alpha$ and 

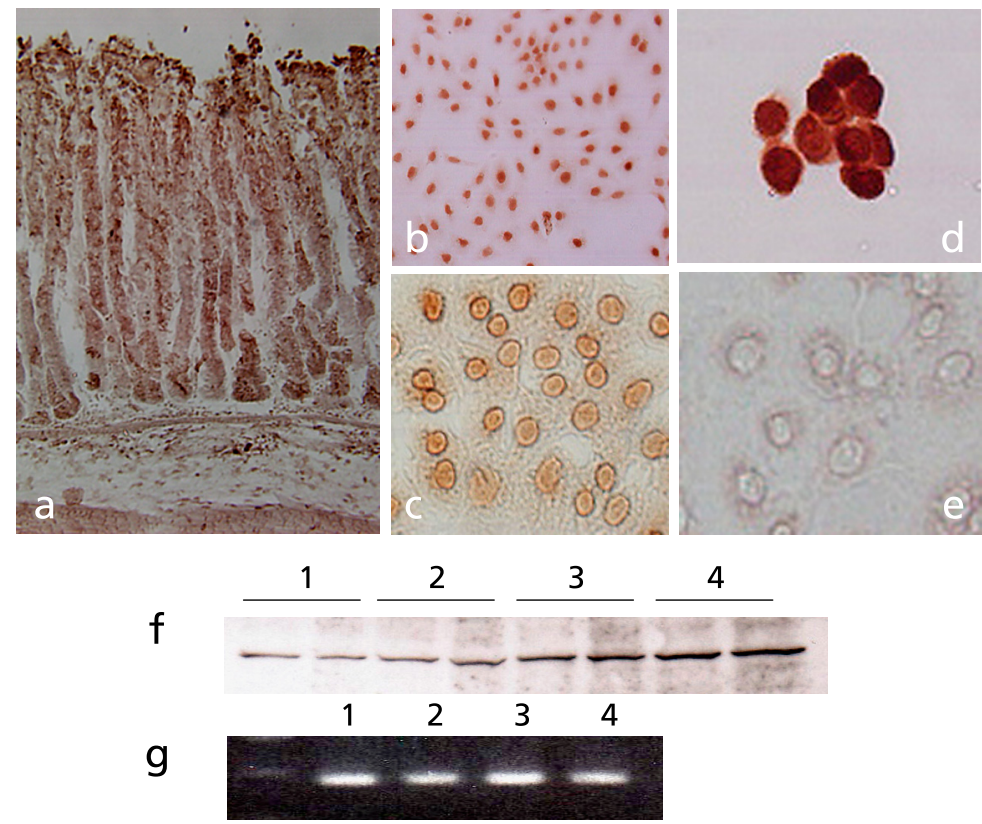

Fig. 1. (a) Immunohistochemical staining for PPAR- $\gamma$ in stomach tissue of rats. (b-e) Nuclear localization of PPAR- $\gamma$ in RGM-1 cells (b, $\times 50, c, \times 200$, e, negative control) and MKN45 cells $(\mathrm{d}, \times 200)$. ( $\mathrm{f})$ Western blot detection of PPAR- $\gamma$ protein in homogenates of gastric mucosal tissues before and after ischemia-reperfusion (I-R). (g) Expression of PPAR- $\gamma$ mRNA in the gastric mucosa determined by RT-PCR. 1, sham-operation, 2, ischemia-reperfusion, 3 , ischemia-reperfusion + pioglitazone $(10 \mathrm{mg} / \mathrm{kg}), 4$, sham + pioglitazone.

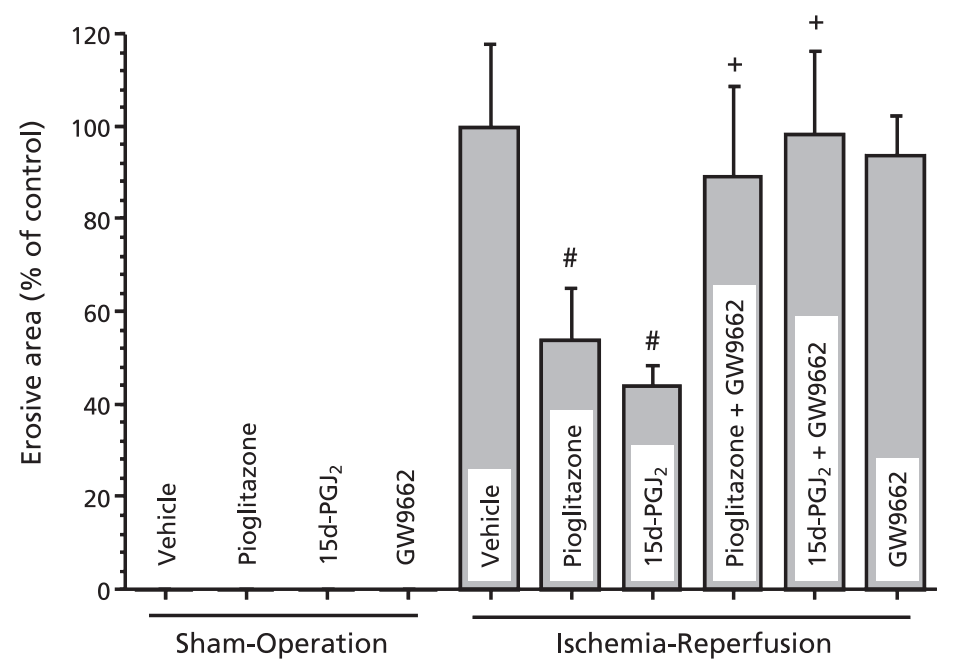

Fig. 2. Effect of pioglitazone and 15-deoxy- $\Delta^{12,14}$-prostaglandin $J_{2}\left(15 d-P G J_{2}\right)$ on acute gastric mucosal injury induced by ischemia-reperfusion (I-R) in rats. Multiple hemorrhagic erosions with acute edema developed in the glandular stomach of rats after 30 -min ischemia and 60 -min reperfusion, and pioglitazone $(10 \mathrm{mg} / \mathrm{kg})$ and $15 \mathrm{~d}-\mathrm{PGJ} 2(0.3 \mathrm{mg} / \mathrm{kg})$ significantly inhibited the total area of gastric erosions induced by I-R. GW9662 significantly reversed the inhibition by these ligands against I-R-induced gastric injury. Data are expressed as mean (SEM) of 7 rats. $\# p<0.05$ when compared to control rats treated with $\mathrm{I}-\mathrm{R}$, and $+p<0.05$ when compared to rats treated with I-R plus pioglitazone or dimethyl PGJ.

CINC-1 production, we analyzed gastric expression of TNF- $\alpha$ and CINC-1 using RT-PCR yielding 225 and 907 base pair products to identify TNF- $\alpha$ and CINC-1 gene expression, respectively. As shown in Fig. 3c, we found the expression of these genes in the rat treated with sham-operation to be negligible or faint. In contrast, transcription was readily shown in I-R-treated rats. Treatment with pioglitazone suppressed mRNA expression for each gene. In addition, pioglitazone markedly inhibited the CINC-1 production from RGM-1 cells stimulated by 2 h-anoxia and 6 h-reoxygenation (Fig. 3d).

Identification of genes differentially expressed in pioglitazone-treated gastric mucosa. We next asked what genes are modulated following treatment of gastric mucosa with pioglitazone and if there are differences between the affected gene networks in pioglitazone-treated mucosa compared to non-treated mucosa. Among the 1,032 probes (Rat Toxicology U34 array, Affymetrix), the number of genes, the expression levels of which increased or decreased more than 1.5 -fold in pioglitazone-treated 
A

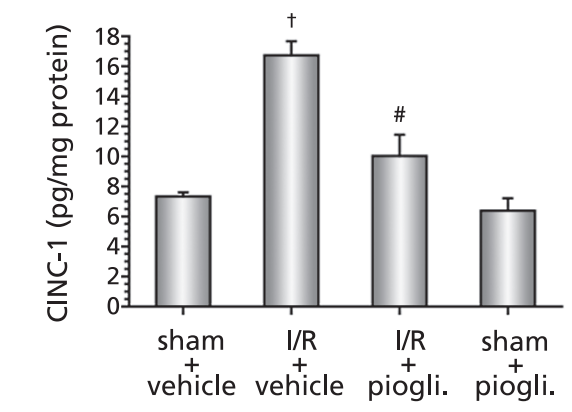

C

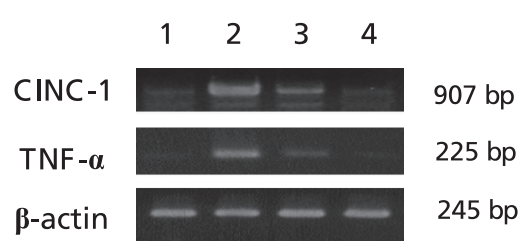

B
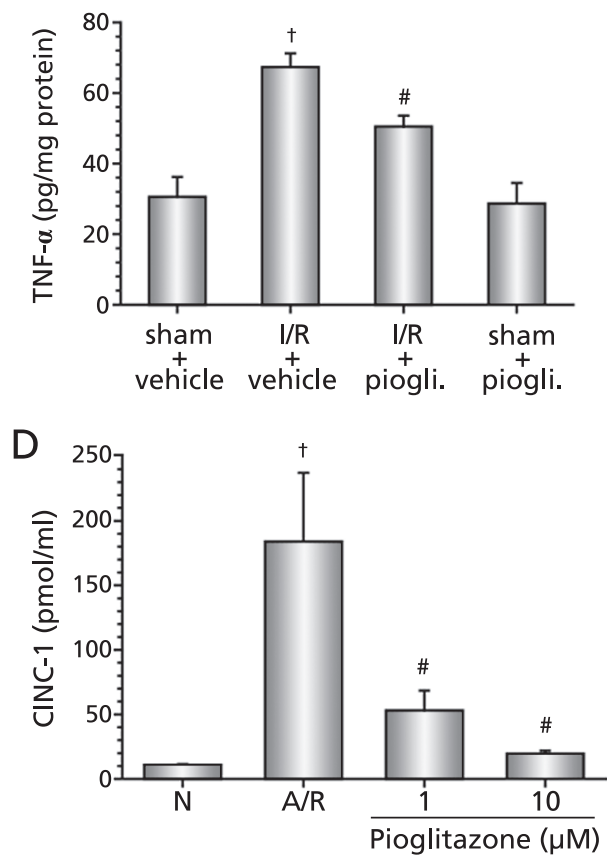

Fig. 3. Effect of pioglitazone on CINC-1 contents (A), TNF- $\alpha$ contents (B), the gastric expression of CINC-1/TNF- $\alpha$ mRNA determined RT-PCR (C), and CINC-1 production from RGM-1 cells stimulated by anoxia-reoxygenation (D). The concentration of CINC-1/TNF- $\alpha$ in the supernatant of mucosal homogenates was determined by ELISA kit specific for rat CINC-1 and rat TNF- $\alpha$. (A, B); Value reported as the mean \pm SE of 6 to 8 rats. ${ }^{\dagger} p<0.01$ when compared to sham-operated rats receiving $0.5 \%$ CMC solution (vehicle) alone, and $\#<0.05$ when compared to rats receiving vehicle plus ischemiareperfusion (I-R). (C); A representative $2 \%$ agarose gel of RT-PCR products for CINC-1 and TNF- $\alpha$ mRNA is shown, also including $\beta$-actin mRNA. (D). ${ }^{+} p<0.01$ when compared to normoxia (N), and ${ }^{*} p<0.05$ when compared to anoxia-reoxygenation (A/R).

mucosa, was 35 including 10 ESTs. 18 probes were up-regulated and 17 were down-regulated (Table 1). Table 2 showed a gene network affected by pioglitazone, which obtained a most highest score (score 14) as defined by the Pathway Analysis, and Fig. 4 demonstrated the associated network that was significantly affected by pioglitazone. The shown network was significantly associated with cell cycle, cell-to-cell signaling and interaction, and cancer. This network included CANX, ERP70, heat-shock protein 60 (HSP60), HSPA5, HSPCA, and PSMB4 genes.

Real time PCR for CANX, ERP70, HSP60, HSPA5, and HSPCA genes. To confirm the data derived from GeneChip analysis, we further validated the expression of some genes by real-time quantitative PCR. As shown in Fig. 5, real time PCR study showed that the expression of CANX, ERP70, HSPCA, and PSMB4, but not HSPA5, was significantly increased by the treatment with pioglitazone.

\section{Discussion}

In the present, we demonstrated the gastric expression of PPAR$\gamma$ in rats by the immunohistochemistry and Western blotting using a monoclonal antibody for PPAR- $\gamma$, and by mRNA expression for PPAR- $\gamma$, and showed that GW9662, a PPAR- $\gamma$ antagonist, reversed the gastro-protective effects of pioglitazone and $15 \mathrm{~d}-\mathrm{PGJ}_{2}$ against I-R injury. In addition, enhanced expression of proinflammatory cytokines in the stomach after I-R was markedly inhibited by pioglitazone. Finally, the global analysis of mRNA expression of gastric mucosal cells obtained by the microdissection showed that up- and down-regulated genes after the pioglitazone treatment, and that anti-inflammatory effects of pioglitazone may be associated with the up-regulation of HSPs and endoplasmic reticulum-related proteins.

The most striking findings of the present study are that expres- sion of PPAR $-\gamma$ is observed in mainly gastric epithelial cells in vivo and in cultured normal gastric epithelial cell line, which was confirmed by immunohistochemistry, Western blot, and RT-PCR. This is the first report in which the gastric PPAR- $\gamma$ expression in rats is confirmed. More interestingly, the expression of PPAR- $\gamma$ protein in the stomach was enhanced after the treatment of pioglitazone without increased mRNA transcription, indicating that pioglitazone may stabilize the protein of PPAR $-\gamma$. In contrast to a previous report uisng renal cells by Matsuyama et al., (26) PPAR- $\gamma$ expression was not enhanced after ischemia-reperfusion in rats. Although the mechanism in regulating gastric mucosal PPAR- $\gamma$ expression is still unknown, the present data using DNA microarray may give possible information about it.

In order to confirm whether the protective effect of PPAR- $\gamma$ ligands is due to activation of PPAR- $\gamma$, we have investigated whether the PPAR- $\gamma$ antagonist GW9662 attenuates the observed protective effects of these ligands. We demonstrate here that GW966 completely reversed the gastro-protective effects of pioglitazone and $15 \mathrm{~d}-\mathrm{PGJ}_{2}$ against I-R injury. Recently, Wada et al. ${ }^{(17)}$ further defined the protective effects of endogenous PPAR- $\gamma$ activity in gastric injury induced by I-R through an examination of PPAR- $\gamma$-deficient mice. They provided strong evidence in support of an important role for endogenous PPAR- $\gamma$ activity in protecting from I-R injury in the stomach. Taken together, these findings support the view that the activation of PPAR $-\gamma$ contributes to the protective and anti-inflammatory effects of PPAR- $\gamma$ ligands in rats subjected to gastric I-R.

The next meaningful finding of the present study is that treatment with pioglitazone significantly inhibited I-R-driven activation of proinflammatory cytokines (CINC-1 and TNF- $\alpha$ ) both in vivo (gastric mucosa) and in vitro (cultured gastric epithelial cells). We demonstrated that, in I-R-induced gastric inflammation, the expression of pro-inflammatory cytokines (CINC-1 and TNF- 
Table 1. Selected genes up- or down-regulated by pioglitazone treatment in rats

\begin{tabular}{|c|c|c|c|c|c|c|c|}
\hline \multirow{2}{*}{ Probe Set ID } & \multirow{2}{*}{ Description } & \multicolumn{2}{|c|}{ Pioglitazone } & \multicolumn{2}{|c|}{ Normal } & \multirow{2}{*}{$\begin{array}{l}\text { Log } \\
\text { Ratio }\end{array}$} & \multirow{2}{*}{$\begin{array}{l}\text { Fold } \\
\text { difference }\end{array}$} \\
\hline & & Intensity & Detection & Intensity & Detection & & \\
\hline \multicolumn{8}{|l|}{ Up-regulated } \\
\hline rc_Al236601_at & $\begin{array}{l}\text { strong similarity to mouse heat-shock protein } 105 \mathrm{kDa} \text {, } \\
110 \mathrm{kDa} \text { protein }\end{array}$ & 404.4 & $\mathrm{P}$ & 101.1 & A & 3.1 & 8.57 \\
\hline rc_Al176546_at & heat shock protein 86 & 2691.4 & $\mathrm{P}$ & 724 & $\mathrm{P}$ & 2 & 4 \\
\hline K00996mRNA_s_at & cytochrome P450, 2b19 & 1098.4 & $\mathrm{P}$ & 400 & A & 1.7 & 3.25 \\
\hline rc_Al010725_g_at & calnexin & 614.6 & $\mathrm{P}$ & 126.2 & A & 1.7 & 3.25 \\
\hline J05132_s_at & UDP glycosyltransferase 1 family, polypeptide A6 & 8504.1 & $\mathrm{P}$ & 2629.8 & $\mathrm{P}$ & 1.4 & 2.64 \\
\hline M14050_s_at & heat shock 70kD protein 5 & 853 & $\mathrm{P}$ & 374.2 & $\mathrm{P}$ & 1.4 & 2.64 \\
\hline rc_Al009141_at & Transcribed sequences & 315.8 & $\mathrm{P}$ & 141.9 & A & 1.4 & 2.64 \\
\hline rC_Al236795_s_at & $\begin{array}{l}\text { Rattus norvegicus heat[-]shock protein } 90 \text { beta mRNA, } \\
\text { partial sequence }\end{array}$ & 6173.3 & $\mathrm{P}$ & 2105.4 & $\mathrm{P}$ & 1.4 & 2.64 \\
\hline L17127_g_at & proteasome (prosome, macropain) subunit, beta type 4 & 772.1 & $\mathrm{P}$ & 286.7 & $\mathrm{P}$ & 1.3 & 2.46 \\
\hline rC_Al172452_at & $\begin{array}{l}\text { weak similarity to cytochrome-c oxidase (EC 1.9.3.1) chain } \\
\text { VIla precursor - rat }\end{array}$ & 1114.6 & $\mathrm{P}$ & 363.5 & $A$ & 1.3 & 2.46 \\
\hline rc_AA859957_at & $\begin{array}{l}\text { moderate similarity to NADH dehydrogenase } 1 \text { beta } \\
\text { subcomplex, } 4\end{array}$ & 1152.9 & $\mathrm{P}$ & 706 & A & 1.2 & 2.3 \\
\hline rC_Al010725_at & calnexin & 686.4 & $\mathrm{P}$ & 356.8 & $\mathrm{P}$ & 1.1 & 2.14 \\
\hline M86870_at & $\begin{array}{l}\text { protein disulfide isomerase[-]related protein } \\
\text { (calcium-binding protein) }\end{array}$ & 465.7 & $\mathrm{P}$ & 239.4 & $\mathrm{P}$ & 0.8 & 1.74 \\
\hline X54793_at & heat shock protein 60 (liver) & 1504.5 & $\mathrm{P}$ & 816.4 & $\mathrm{P}$ & 0.8 & 1.74 \\
\hline \multicolumn{8}{|l|}{ Down-regulated } \\
\hline rc_AA891651_g_at & $\begin{array}{l}\text { moderate similarity to NADH dehydrogenase acyl carrier } \\
\text { chain, mitochondrial }\end{array}$ & 348 & A & 705.1 & $\mathrm{P}$ & -0.8 & 0.57 \\
\hline rC_AA818226_s_at & cytochrome $c$ oxidase, subunit $4 a$ & 2388.7 & $\mathrm{P}$ & 5302.6 & $\mathrm{P}$ & -0.9 & 0.54 \\
\hline rC_AA900199_s_at & Rattus norvegicus DD6C4-4 mRNA, partial sequence & 345.5 & M & 695.8 & $\mathrm{P}$ & -0.9 & 0.54 \\
\hline rC_AA892041_at & peroxiredoxin 6 & 411.5 & A & 849.8 & $\mathrm{P}$ & -1.2 & 0.44 \\
\hline rc_Al102505_g_at & cytochrome c oxidase, subunit VIIla & 1560 & $\mathrm{P}$ & 3382.2 & $\mathrm{P}$ & -1.3 & 0.41 \\
\hline rc_Al177256_at & Transcribed sequences & 263.6 & A & 986.5 & $\mathrm{P}$ & -1.5 & 0.35 \\
\hline rc_AA963674_at & eukaryotic translation elongation factor 2 & 1132.1 & $A$ & 3972.2 & $\mathrm{P}$ & -1.6 & 0.33 \\
\hline 278279_at & collagen, type 1, alpha 1 & 146.9 & A & 327.3 & M & -1.7 & 0.31 \\
\hline rc_AA945054_s_at & cytochrome b5 & 186.3 & A & 637.5 & $\mathrm{P}$ & -1.9 & 0.27 \\
\hline J05425cds_s_at & cytochrome $c$ oxidase, subunit $4 a$ & 218.9 & $A$ & 1097.6 & $P$ & -2.7 & 0.15 \\
\hline
\end{tabular}

Table 2. Genetic networks up-regulated by pioglitazone treatment analyzed by Pathway Analysis

\begin{tabular}{|c|c|c|c|c|}
\hline Network ID & Genes in Network & Score & Focus Genes & Top Function \\
\hline 1 & $\begin{array}{l}\text { APOB, BACE, CANX*, CDK4, ERP70, GAPD, HSP60, HSPA4, } \\
\text { HSPA5, HSPCA, IGK@, MYC, PPP1CC, PSMA1, PSMA2, PSMA3, } \\
\text { PSMA4, PSMA5, PSMA6, PSMA7, PSMB1, PSMB10, PSMB2, } \\
\text { PSMB3, PSMB4, PSMB5, PSMB6, PSMB7, PSMB8, PSMB9, } \\
\text { SERPINA1, TRA@, TYR, TYRP1, VWF }\end{array}$ & 14 & 6 & $\begin{array}{l}\text { Cell cycle, Cell-to-Cell Signaling } \\
\text { and Interaction, Cancer }\end{array}$ \\
\hline
\end{tabular}

Bold - Up[-]regulated fo[c]us genes. Gene/Protein identified that made the user-defined cutoff and map to the Global Molecular Network are displayed with bold text. *-Duplicates. Gene IDs marked with asterisks indicate that multiple identifiers from our input list mapped to a single gene in the Global Molecular Network.

CANX, calnexin; ERP70, endoplasmic reticulum stress protein 72; HSP60, heat-shock protein 60; HSPA5, heat-shock 70 kD protein 5; HSPCA, heat-shock protein 86; PSMB4, proteasome subunit beta type4.

a) was enhanced in association with neutrophil accumulation, as determined by myeloperoxidase activity in the homogenate of the stomach. ${ }^{(27)}$ These results suggest a transcriptional mechanism by which PPAR- $\gamma$ agonists may protect against gastric mucosal injury via an inhibition of cytokine production.

Finally, to investigate cytoprotective action by pioglitazone further, we compared the gene expression profiles between vehicle- and pioglitazone-treated gastric mucosal cells. By the pathway analysis, we demonstrated the associated network that was significantly affected by pioglitazone. The shown network was associated with cell cycle, cell-to-cell signaling and interaction, and cancer. This network includes CANX, ERP70, HSP60, HSPA5, HSPCA, and PSMB4 genes, and the mRNA expression of these genes were also confirmed by real-time PCR. In eukaryotic cells, the endoplasmic reticulum (ER) plays an essential role in the synthesis and maturation of a variety of important secretary and membrane proteins. For glycoprotein, the ER possesses a dedicated maturation system, which assists folding and ensures the quality of final products before ER release. Essential components of this system include the lectin chaperones CANX and calreticulin (CRT) and their associated co-chaperone ERP, a glycoprotein specific thiol-disulfide oxidoreductase. ${ }^{(28)}$ These data suggest that ER stress response induced by pioglitazone may be associated with its anti-inflammatory or cytoprotective actions on gastric mucosa. This hypothesis is supported by a recent report, in which $15 \mathrm{~d}-\mathrm{PGJ}_{2}$ a PPAR- $\gamma$ ligand, induced ER stress, and that 


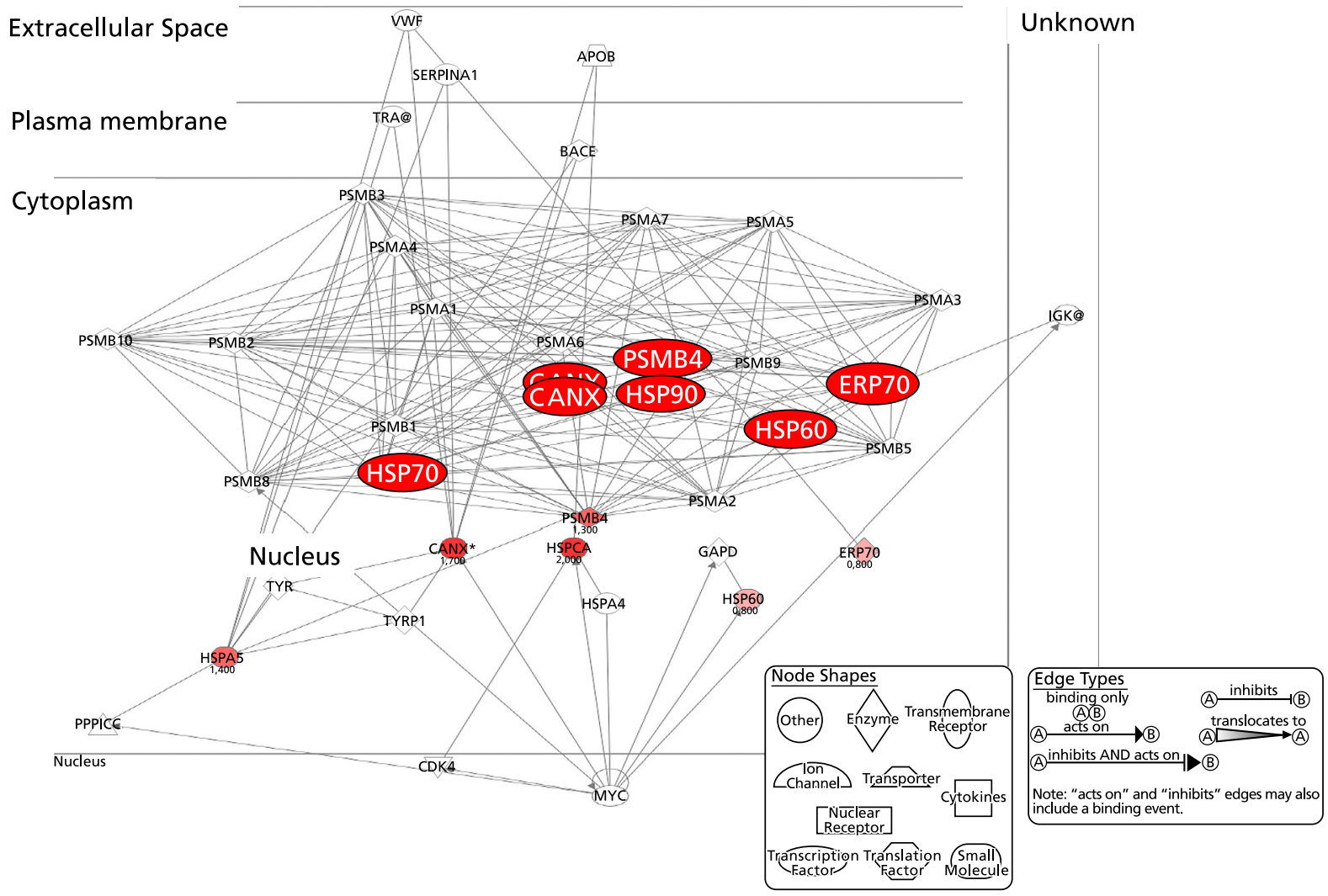

Fig. 4. A network of genes commonly regulated after pioglitazone treatment. Seven genes that were up-regulated in pioglitazone-treated stomach were analyzed by the Ingenuity Pathway Analysis tool. The shown major network that was found to be significantly up-regulated by pioglitazone was associated with cell cycle, cell-to-cell signaling and interaction, and cancer. Shaded genes are the genes identified by microarray analysis and others are those associated with the regulated genes based on the pathway analysis. The meaning of the node shapes is also indicated. Asterisks indicate genes that were identified multiple times.
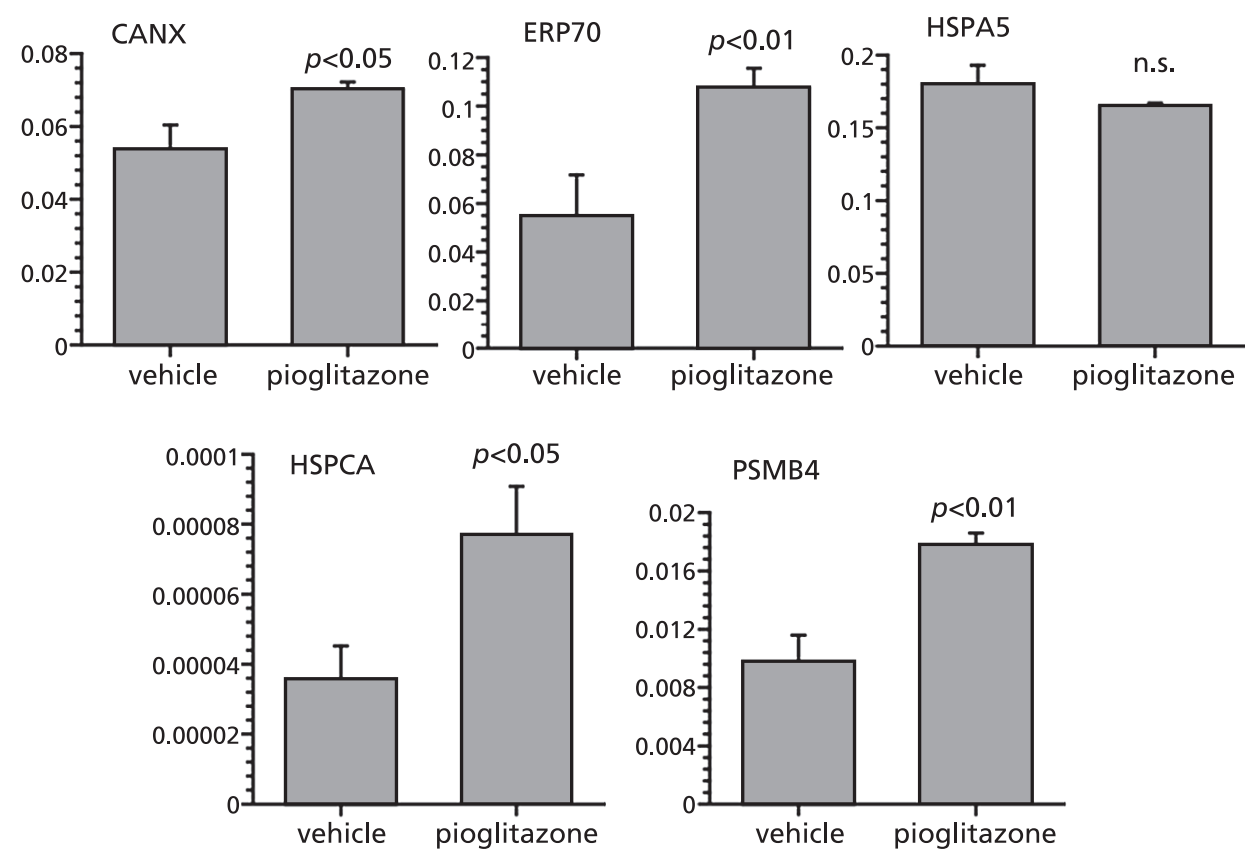

Fig. 5. Quantitative real-time PCR for genes up-regulated by pioglitazone treatment. CDNA was prepared from gastric mucosa, and PCR was performed using an ABI 7300. The bars show levels of expression of each gene normalized to that of $\beta$-actin. 
ER stress activation was associated with an attenuation of cytokine signaling in pancreatic $\beta$-cells. ${ }^{(29)}$

In summary, we confirmed the expression of PPAR- $\gamma$ in the rat gastric mucosa, and determined that the gastroprotective action of PPAR- $\gamma$ ligand was dependent on the activation of the PPAR- $\gamma$ receptor. Finally, we demonstrated that DNA microarray was a highly effective way to generate a novel hypothesis on mechanism of action of PPAR- $\gamma$ ligand. In conclusion, activation of PPAR- $\gamma$ may represent a novel therapeutic approach for the therapy of gastric inflammation.

\section{Acknowledgments}

This work was supported by a Grant-in-Aid for Scientific Research (B) to T.Y. (no. 21390184) and Scientific Research (C) to Y.N. (no. 22590705), by a City Area Program to T.Y. and Y.N.

\section{References}

1 Zinner MJ, Turtinen L, Gurll NJ. The role of acid and ischemia in production of stress ulcers during canine hemorrhagic shock. Surgery 1975; 77: 807-816.

2 Kitajima M, Shimizu A, Sakai N, and et al. Gastric microcirculation and its regulating factors in stress. J Clin Gastroenterol 1991; 13 Suppl 1: S9-S17.

3 Takeuchi K, Ueshima K, Hironaka Y, Fujioka Y, Matsumoto J, Okabe $\mathrm{S}$. Oxygen free radicals and lipid peroxidation in the pathogenesis of gastric mucosal lesions induced by indomethacin in rats. Relation to gastric hypermotility. Digestion 1991; 49: 175-184.

4 Murakami M, Asagoe K, Kusaka S, Kita T. Effect of gastric mucosal blood flow on the pathogenesis of ammonia in Helicobacter pylori-induced gastric mucosal injury. Eur J Gastroenterol Hepatol 1994; 6 Suppl 1: S45-S47.

5 Perry MA, Wadhwa S, Parks DA, Pickard W, Granger DN. Role of oxygen radicals in ischemia-induced lesions in the cat stomach. Gastroenterology 1986; 90: 362-367.

6 Yoshikawa T, Ueda S, Naito Y, and et al. Role of oxygen-derived free radicals in gastric mucosal injury induced by ischemia or ischemiareperfusion in rats. Free Radic Res Commun 1989; 7: 285-291.

7 Naito Y. Role of superoxide anion radical in acute gastric mucosal and vascular injury induced by ischemia-reperfusion in rats. J Kyoto Pref Univ Med 1993; 102: 87-106.

8 Itoh M, Guth PH. Role of oxygen-derived free radicals in hemorrhagic shock-induced gastric lesion in the rats. Gastroenterology 1985; 88: 1162 1167.

9 Lemberger T, Desvergne B, Wahli W. Peroxisome proliferator-activated receptors: a nuclear receptor signaling pathway in lipid phisiology. Ann Rev Cell Dev Biol 1996; 12: 335-363.

10 Schoonjans K, Martin G, Staels B, Auwerx J. Peroxisome proliferatoractivated receptors, orphans with ligands and functions. Curr Opin Lipidol 1997; 8: 159-166.

11 Jiang C, Ting AT, Seed B. PPAR-gamma agonists inhibit production of monocyte inflammatory cytokines. Nature 1998; 391: 82-86.

12 Ricote M, Li AC, Willson TM, Kelly CJ, Glass CK. The peroxisome proliferator-activated receptor-gamma is a negative regulator of macrophage activation. Nature 1998; 391: 79-82.

13 Naito Y, Yoshikawa T. Thiazolidinediones: a new class of drugs for the therapy of ischemia-reperfusion injury. Drugs Today (Barc) 2004; 40: 423-430.

14 Ichikawa H, Naito Y, Takagi T, Tomatsuri N, Yoshida N, Yoshikawa T. A specific peroxisome proliferator-activated receptor-gamma (PPAR-gamma) ligand, pioglitazone, ameliorates gastric mucosal damage induced by is chemia and reperfusion in rats. Redox Rep 2002; 7: 343-346.

15 Konturek PC, Brzozowski T, Kania J, and et al. Pioglitazone, a specific ligand of the peroxisome proliferator-activated receptor gamma reduces gastric mucosal injury induced by ischaemia/reperfusion in rat. Scand $J$ Gastroenterol 2003; 38: 468-476. from Ministry of Education, Culture, Sports, Science and Technology, Japan, and by a Adaptable and Seamless Technology Transfer Program through target-driven R\&D to Y.N. from Japan Science and Technology Agency.

\section{Abbreviations}

CINC cytokine-induced neutrophil chemoattractant

CMC carboxymethyl cellulose

EMSA electrophoretic mobility shift assay

$\mathrm{I}-\mathrm{R} \quad$ ischemia-reperfusion

MPO myeloperoxidase

PPAR peroxisome proliferator-activated receptor

RT-PCR reverse-transcription polymerase chain reaction

TZD thiazolidinedione

16 Villegas I, Martin AR, Toma W, de la Lastra CA. Rosiglitazone, an agonist of peroxisome proliferator-activated receptor gamma, protects against gastric ischemia-reperfusion damage in rats: role of oxygen free radicals generation. Eur J Pharmacol 2004; 505: 195-203.

17 Wada K, Nakajima A, Takahashi H, and et al. Protective effect of endogenous PPARgamma against acute gastric mucosal lesions associated with ischemia-reperfusion. Am J Physiol Gastrointest Liver Physiol 2004; 287: G452-G458.

18 Takagi T, Naito Y, Ichikawa H, and et al. A PPAR-gamma ligand, 15-deoxyDelta12,14-prostaglandin $\mathrm{J}(2)$, inhibited gastric mucosal injury induced by ischemia-reperfusion in rats. Redox Rep 2004; 9: 376-381.

19 Naito Y, Takagi T, Matsuyama K, Yoshida N, Yoshikawa T. Pioglitazone, a specific PPAR-gamma ligand, inhibits aspirin-induced gastric mucosal injury in rats. Aliment Pharmacol Ther 2001; 15: 865-873.

20 Slomiany BL, Slomiany A. Suppression of gastric mucosal inflammatory responses to Helicobacter pylori lipopolysaccharide by peroxisome proliferatoractivated receptor gamma activation. IUBMB Life 2002; 53: 303-308.

21 Nakajima A, Wada K, Miki H, and et al. Endogenous PPAR gamma mediates anti-inflammatory activity in murine ischemia-reperfusion injury. Gastroenterology 2001; 120: 460-469.

22 Kobayashi I, Kawano S, Tsuji S, and et al. RGM1, a cell line derived from normal gastric mucosa of rat. In Vitro Cell Dev Biol -Animal 1996; 32: 259261.

23 Inauen W, Granger DN, Meininger CJ, Schelling ME, Granger HJ, Kvietys $\mathrm{PR}$. An in vitro model of ischemia/reperfusion-induced microvascular injury. Am J Physiol 1990; 259: G134-G139.

24 Katada K, Naito Y, Shimozawa M, and et al. Gene expression analysis following hypoxia-reoxygenation in rat gastric epithelial cells using a highdensity oligonucleotide array. Redox Rep 2004; 9: 337-342.

25 Naito Y, Uchiyama K, Kuroda M, and et al. Laser capture microdissection/ GeneChip analysis of gene expression in glomerular cells in diabetic $\mathrm{db} / \mathrm{db}$ mice. Redox Rep 2004; 9: 307-312.

26 Matsuyama M, Yoshimura R, Hase T, and et al. Expression of peroxisome proliferator-activated receptor-gamma in renal ischemia-reperfusion injury. Transplant Proc 2005; 37: 1684-1685.

27 Yoshikawa T, Naito Y. The role of neutrophils and inflammation in gastric mucosal injury. Free Radic Res 2000; 33: 785-794.

28 Ellgaard L, Frickel EM. Calnexin, calreticulin, and ERp57: teammates in glycoprotein folding. Cell Biochem Biophys 2003; 39: 223-247.

29 Weber SM, Chambers KT, Bensch KG, Scarim AL, Corbett JA. PPARgamma ligands induce ER stress in pancreatic beta-cells: ER stress activation results in attenuation of cytokine signaling. Am J Physiol Endocrinol Metab 2004; 287: E1171-E1177. 